\title{
An "Embedded" Mode of International Talent Training Boosts the Two-Way Opening of Higher Education
}

\author{
Weibo Zheng1, Yilei Wen'1, Lu Zheng² \\ ${ }^{1}$ College of Business Administration, Hebei University of Economics and Business, Shijiazhuang, China \\ ${ }^{2}$ School of Mathematical of Sciences, Tianjin Polytechnic University, Tianjin, China \\ Email:693698511@qq.com
}

How to cite this paper: Zheng, W.B., Wen, Y.L. and Zheng, L. (2019) An "Embedded" Mode of International Talent Training Boosts the Two-Way Opening of Higher Education. Open Journal of Social Sciences, 7, 136-145.

https://doi.org/10.4236/jss.2019.73010

Received: November 29, 2018

Accepted: March 10, 2019

Published: March 13, 2019

\begin{abstract}
The Belt and Road Initiative (BRI) introduces new demands for international talents, and the strategy for the coordinated development of Beijing, Tianjin and Hebei Province which gives new opportunities to train such talents in Hebei Province. In this context, relevant adjustments shall be made into the training of international talents in order to better meet the needs of the times. This paper outline the "embedded" international talent cultivation, a practice carried out in Hebei in the two-way opening of higher education, which is aim to cultivate international management talents who understand international laws, master economic management expertise in the context of globalization, have innovative ability, cross-cultural competence, practical ability and high foreign language ability, are familiar with international business activities and rules, and able to work in enterprises and institutions. It is a practice to pose quality education resources from abroad while building on cultural confidence. This article also offers a peek into the export of culture and its contribution to the two-way opening of higher education.
\end{abstract}

\section{Keywords}

Embedded Mode, Cooperative Education, Two-Way Opening of Higher Education

\section{Two-Way Opening of Higher Education}

The "Belt and Road Initiative" is a grand economic vision that promotes mutually beneficial cooperation between Asia, Europe and Africa in infrastructure, investment and trade, and humanities exchanges. It has far-reaching impact on 
China and countries from all over the world, and is based on changes in the domestic and international situations to come up with the new reform and opening up strategy. The "Belt and Road initiative" of the 19th National Congress provides a historical opportunity for international talent training, and poses new challenges for international talent training. It is proficient in foreign languages and can smoothly carry out policies, projects, finance, commerce and other aspects with relevant countries. The demand for cooperative international talent has increased rapidly [1].

The coordinated development strategy of Beijing-Tianjin-Hebei provides a possibility for the development of international talent training in Hebei Province. The construction of Xiong'an New District has become a strong economic growth pole. How does Hebei Province grasp this great historical opportunity? Hebei Province has stood on the "trend" of international talent training supply. In addition to responding to the demand for international talents that will be expanded, it is also necessary to face the equalization of international educational opportunities and the functional changes of international education in regional universities. In December 2017, China cooperated with 7 countries along the "Belt and Road" countries including Russia, Poland, Singapore, India and Belarus to carry out 146 undergraduate and above-level educational institutions and projects. Most of the institutions and projects have been established in recent years. The sharing of educational resources makes the two-way opening of higher education inevitable [2]. Among them, Sino-foreign cooperative education as the main way of educating internationalization and internationalized personnel training, simply discussing from the "should be" or "what kind of Sino-foreign cooperative education model universities should adopt" is not the mission of this article. Rather, under the background of the global economy and the urgency of the times, it is necessary to study from the perspective of "actually" or "how universities actually need to use the Sino-foreign cooperative education model" to realize the two-way opening of higher education. In order to improve opening level, this article presents some ideas which are combining "leveled" "go out" "bring in" in the aspect of international exchange and cooperation in running, personnel globalization, internationalization of educational resources [3]. How to adjust the education concept and create a new talent training model to create a high-quality, high-quality international compound talent?

In order to improve the level of openness to higher education, this paper proposes a strategic approach that combines "stratification", "going out" and "bringing in" in terms of international exchanges and cooperation in running schools, internationalization of personnel, and internationalization of educational resources. In order to achieve the goal of internationalization of education, it will further expand the influence of higher education in the international community.

\section{International Talent Training}

The "One Belt, One Road" initiative is not only a one-way "introduction". At 
present, China's education "introduction" and "going out" are classified and managed. Sino-foreign cooperative education is a combination of "bringing in" and "going out". It is an important measure to promote the development of two-way open education in China. From the perspective of the practice of Sino-foreign cooperative education, the main body of cooperative education for internationalized personnel training presents a diversity of status, and local colleges and universities become an important subject of international education [4].

The current "One Belt and One Road" strategy and the "double first-class" construction of colleges and universities have become an important opportunity for the development of Sino-foreign cooperative education [5]. On the basis of the balance between talent training funds and resource allocation, this paper will introduce advanced education models and educational resources to achieve a high level of high education balance among teachers, students and schools; at the same time, will enlarge the flow and communication of talents. The institutional barriers are aim to achieve new developments in regional international talents. The infrastructure of colleges and universities in Hebei Province is solid, and the geographical advantages can be fully connected with the famous schools of Beijing and Tianjin.

In recent years, the national and local education administrations have issued relevant guidance and tried to remedy the repetitive low-quality specialties setting in Sino-foreign cooperative education. Initial results have been obtained. However, the long-lasting deep-level contradictions in relation to specialty setting have not been resolved. One-sided profit-seeking and blind "cooperative education" have caused the "chain stores" of foreign-invested universities in the field of Sino-foreign cooperative education [6]. Seeking a better development of talent training in Beijing-Tianjin-Hebei, China has made efforts to introduce many levels international education resources, in order to fulfill new achievements in the cultivation of international talents in the three regions. As Figure 1

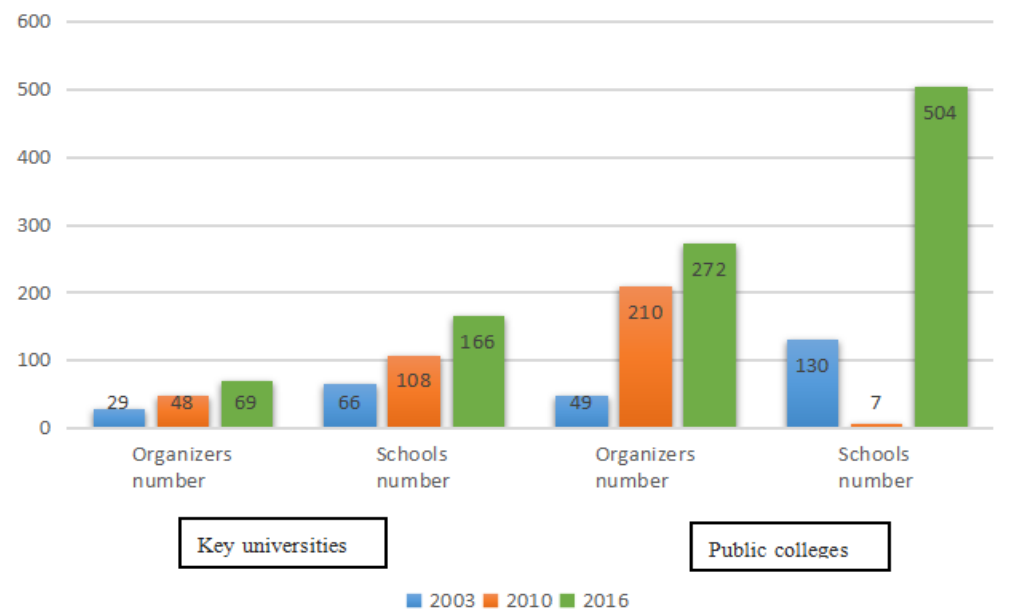

Figure 1. Variation trend of operators of Sino-foreign cooperative education programs during 2003-2016. 
shows, such cooperative education programs run by colleges under local authorities account for nearly half the total Sino-foreign cooperative education programs run by colleges and universities. Still, colleges under local authorities have huge potential for such cooperative endeavor. The elements of international innovative talent training mode in Sino-foreign cooperative education are under a dynamic relationship that requires continuous adjustment. It is not a reform on a local part, detail or element but an overall reform on international innovative talent training.

As local colleges and universities become the main force in the cultivation of international talents, cross-cultural issues are also increasingly prominent [7]. In a short, the number is gradually increasing, the enrollment is large-scale; the regional distribution is extensive, the layout still needs to be optimized; the disciplines are widely covered, and the school-running structure is still to be optimized [8]. "Culture" is breaking through national barriers and geographical boundaries in international exchanges and spreading on a global scale [9]. Cultural conflict and adaptation are important issues in the cultivation of international talents. The educational dilemma of students' cross-cultural adaptation is mainly reflected in the cultural conflicts in the value concept, the cultural conflicts in the educational concept, the cultural conflicts in the thinking mode, the cultural conflicts in the students' self-learning and identification, and even the cultural shock phenomenon.

\section{Embedded Mode of International Talent Training}

When it comes to the modes of Sino-foreign cooperative education, there are mainly three modes, namely loose mode, grafted mode, and the integrated mode in theory. Loose mode involves inviting foreign teachers to give lectures, an approach to align the teaching with the international practice. The grafted mode involves the introduction of foreign education resources in their original forms, but it is likely that what is introduced into China may prove to be entirely irrelevant. In addition, since it is mainly about the combination of teaching materials, teachers and evaluation methods in the colleges running such programs, while both sides are allowed to keep their teaching methods, it is likely that problems may arise with student management and alignment of teaching and learning. In the integrated mode, the teaching modes at home and abroad are completely integrated, but it takes hard work to achieve the goals. In the long run, imposing unified standard in all cases and the lack of a personalized evaluation system will inevitably lead to the nearly identical talent training modes. Additionally, Sino-Chinese cooperative education evaluation is just to evaluate the conformity of education. In order to adapt to the needs of the new high-level demonstrative development stage for such education, an appraising system should also be built to summarize and publicize the demonstrative Sino-foreign cooperative education providers and programs and their brand specialties, quality courses (group) and advanced training approaches and provide valuable ref- 
erence for high-quality innovative talent training modes of these education providers and programs of the same type.

The "introduction" in international cooperation in running schools is not an end. What matters is a full localization of what is introduced into China, which will lead to innovation. So universities must pursue a cooperation of "introduction-innovation-development". In this sense, the embedded mode is an "initiative" pattern re-factoring, with an attention focused on the converging point of training institutions, individual talents, enterprises or organizations in need of a comprehensive talent training mechanism, and an emphasis placed on the connectivity among all the stakeholders. It is necessary to base on the comprehensiveness and integrity of international innovative talent training mode reform in Sino-foreign cooperative education and make a breakthrough in balancing the relationship among administrative departments, main school-running participants and faculty so as to give play to the administration functions of macro-guidance and reform support and bring into play the key role of $\mathrm{Si}$ no-foreign cooperative education and programs.

The introduction of this system into the construction of an international talent training model refers to the compound talent training mechanism. There are "intersection points" between training institutions, individual talents, demand enterprises or organizations, and "embed" into the research field of higher education internationalization talents, emphasizing the closeness of all-round multi-stakeholder "relationship networks". From the perspective of comprehensive reform, joint efforts should be made among government, universities and programs and the awareness of main participants and responsibility of Sino-foreign cooperative education providers should be enhanced. A strict accountability system should be built to ascertain specific responsibilities. In the long run, the Sino-foreign cooperative education providers and programs should bring into play the role of main participants of international innovative talent training mode reform. Most importantly, a perfect and scientific international innovative talent training mode operation mechanism should be built inside the education providers. The degree is the "active" model reconstruction under the overall international talent training strategy that explores the needs of regional economic practice at the medium and micro level, and pursues the organic unity of cognitive embedding, cross-cultural embedding, and practice embedding. It is an effective way to cultivate students' interest in cross-cultural communication and improve students' cross-cultural communication level and realize the needs of students and foreign teachers [10]. Behind, it is an overall international talent training strategy, which has been designed to study the regional economic growth. Based on years of cooperative education practice, this paper outlines the development of talent cultivation modes and the new development path is shown in Figure 2. The mode reform can better facilitate the exerting of its own radiating and catfish effect, produce a "forcing mechanism" on domestic higher education reform and promote discipline development and management system innovation [11]. The embedded mode is the exploitative efforts by Hebei's 


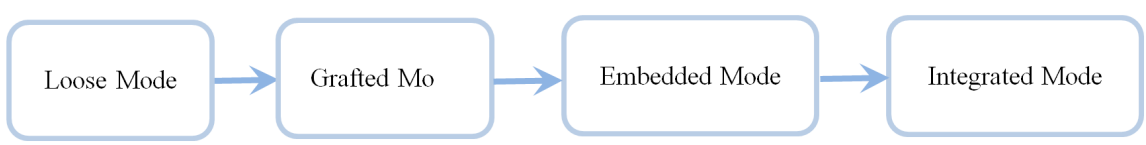

Figure 2. The development path of talent training mode.

colleges and universities in a shift from the "introduction" and "going global" into the two-way resource opening and sharing [12]. It has enriched the modes of international talent training [13].

\section{Two-Way Opening in Colleges in Hebei}

Hebei University of Economics and Business (HUEB) is a college introduce to new ideas and bold for innovation, which has devoted itself to the exploratory practice of the two-way opening of higher education. It has built long-term, fruitful partnership with colleges and universities in more than 40 countries, including the United States, Britain and Australia. In addition, it has made remarkable achievements in promoting Chinese culture, establishing two Confucius institutes with Kathmandu University and University of Zambia. In its international cooperative education, which features the modes of $3+1$, it has made pioneering exploration of the three-level embedded mode of international talent training by drawing on the quality teaching resources from the Chicago-based Concordia University. For example, in terms of adjustment of specialties and discipline layout, not only the needs of local social and economic development should be accurately understood but also suitable partners should be found in the world. Curriculum system reform should reflect both international and local concepts. In terms of talent training quality evaluation, the extensive international evaluation and certification experience should be drawn. Even a cooperative relationship should be established with international certification institutions. And the faculty team should be built with the collaboration of multiple departments.

At the first level, cognition is embedded into the students. That is, it is an active cognitive embedding of critical thinking, coupled with optional implanting of diversified international education resources, in order to strengthen the cultivation and shape critical thinking and an active personality on the part of the students. At the second level, it involves the embedding of cross-cultural adaptation into an organization. In other words, it is a system that enhances the embedded autonomy capabilities of the behavioral agent in a cross-cultural context drive by regional economy. At the third level, the key is to serve core objectives of regional economic development, with a focus on market orientation to underscore the practical embedding organizations in need of talents, colleges running such programs, the embedded teaching has proved a very successful practice. Guided by the Beijing-Tianjin-Hebei development strategy and industrial layout, the optional embedded mode, by drawing on Hebei unique regional advantages, integrating Chinese and American high-quality teaching resources, 
and adopting the flexible double-school running mode, is contributing talents of business management to meet the talent demands of the region for economic growth. The internationalization project of Hebei University of Economics and Business has "went out" through the practice of excellent traditional culture, reducing the sudden cultural conflicts and even the "Culture Shock" phenomenon in the first-time strange countries.

Regarding foreign language teaching as one of the major tasks of Sino-foreign cooperative education not only confuses cause and effect but goes against the initial intention of introducing international quality education resources. In response to cross-cultural adaptation issues, the Sino-foreign cooperative education project of Hebei University of Economics and Business has established a "Lecture + Tutorial + Senior Friends" system to help students break through the bottleneck of professional knowledge while opening bilingual courses for Chinese teachers and introducing foreign teachers to the university. Attach importance to the construction of its own connotation and provide guarantee for international exchanges and cooperation. The application of entrepreneurs into the classroom, business visits, and local cases in teaching has greatly mobilized the enthusiasm of foreign teachers and realized the win-win situation of entrepreneurs, foreign teachers, Chinese teachers and students. What's more, fully exploit the leading role of faculty. It is a bright view that a stable international faculty team should be built. Research finds that the faculty team building of Sino-foreign cooperative education providers and programs are worrying. The teachers introduced by some providers and programs are not from their foreign partners but are those derived from China. Many foreign teachers are language teachers. The term "Flight teaching" is excessively adopted. The intensive teaching by such foreign teachers makes the teaching quality hard to be guaranteed.

There is a common phenomenon that some Chinese education providers do not have proper training objectives but pursue profits only. HUEB need to do a good job in the top-level design of local universities and internationalization, and increase the importance attached to international exchanges and cooperation [14]. The focus of recent planning can be on short-term projects, such as exchange students and teacher exchange programs; medium-term planning can focus on cooperative education projects, such as different levels of Sino-foreign cooperation in running schools and research cooperation; long-term planning can be cooperative colleges or schools construction. At the same time, local colleges and universities realize the effective integration of regional characteristics and international characteristics, and always maintain their own unique advantages in the process of education internationalization, so that obtain their own international education development model. In-depth theoretical research supports international development. The "embedded mode" not only strongly supports the internationalization of higher education in the country, but also contributes to the internationalization of higher education in the world.

Clearly address the goal of international talent training for local economic 
construction, and have the dual participation of talent demand organization and training of colleges and universities. The categorization of China higher education internationalization should combine the direction dimension with the form dimension, there is still room for quality improvement for China higher education inward internationalization and China higher education outward internationalization is undeveloped [15]. Moreover, the active participation of students, the effect of embedded teaching practice is obvious. The selective "embedded" model is based on the unique regional advantages of Hebei Province, integrating high-quality teaching resources between China and the United States, adopting a flexible dual-campus school-running model, and training in the management of talents in accordance with the three-level development strategy and industrial layout of Beijing-Tianjin-Hebei.

\section{Conclusions}

As a key local university in Hebei Province, Hebei University of Economics and Business has always led and practiced the international talent training for local economic needs. Since 2011, HUEB has embarked on an exploitative journey, by proceeding from a dual-perspective of management and education and developed an international talent-training mode, and proved the conductivity of the social and economic development of the region. The international talent training model is suitable for regional economic and social development needs.

Based on Beijing-Tianjin-Hebei strategy, universities devote to meet the needs of local economic development, and cultivate international management talents. If they are familiar with international business activities and rules, they will be able to work in enterprises and institutions. The purpose of university is to cultivate internationalized compound economic management personnel who will be served by units, government departments and multinational enterprises. After fully integrate the high-quality domestic and foreign resources, universities pay attention to the cultivation of students' cross-cultural competence, and adopt the internationalized and diversified teaching methods to exert teaching practice. Besides, student mobility is the dominant form of China higher education outward internationalization, so the continual interplay between inward and outward internationalization will promote the enhancement of China higher education internationalization.

Further, highlighting "self-orientation" and based on a strong confidence in culture, an optional embedded mode has been established, by taking a global vision while taking root in Beijing-Tianjin-Hebei Region, to fully integrate both domestic and foreign high-quality resources, and draw on the practice of embedded mode of talent training. While seeking the chance offered by the two-way opening of higher education, universities should promote the export of Chinese higher education, manage to play a leading role in global education governance and the formulation of international education rules, to provide the world with Chinese wisdom, and share with the world our exploratory achievements of international talent cultivation. 


\section{Acknowledgements}

This work was financially supported by Hebei Social Science Fund (HB17GL049).

\section{Conflicts of Interest}

The authors declare no conflicts of interest regarding the publication of this paper.

\section{References}

[1] Chen, H.Y. (2017) One Belt and One Road Strategy Implementation and New Internationalized Talent Cultivation. Journal of Chinese High Education Research, 6 , 17-19.

[2] Liao, Y.C. (2018) Research on the Internationalization Development of Higher Education under the Background of "Belt and Road". Modern Communication, No. 15, 169-170.

[3] Yue, H.P. (2016) A Study on the Talent Cultivation of Sinoforeign Cooperative Education with Internationalization and Localization. Journal of Science and Culture Education, No. 4, 1-2.

[4] Ye, L. and Wang, Z.T. (2018) Internationalization of China's Higher Education: A Type Framework and Evaluation. Comparative Education Research, 40, 43-52.

[5] Lin, Y.F. (2015) One Belt and One Road and Free Trade Zone: China's New Strategy of Opening to the Outside World. Leading the Way in China.

[6] Chen, Q. and Wen, W. (2018) The OBOR Initiative Chinese Student Education: Mission, Challenges and Countermeasures. Journal of High Education Management.

[7] Sang, Y. (2018) Expanding the Status and Strategy of Higher Education's Opening to the Outside World-Taking the Status of Education Opening in Tianjin Universities as an Example. Education and Teaching Forum, No. 36, 70-71.

[8] Li, S.Y. and Guo, Q. (2018) The Innovation and Development of Sino-Foreign Cooperation in Running Schools in the Process of Internationalization. China Adult Education, No. 14, 31-34.

[9] Wen, J. and Jiang, X.L. (2015) The Way of International Talents Cultivation in Universities by Systematic Thinking. Journal of Business Culture and Education, No. 5.

[10] Wang, T.X. (2018) Cultivation of Students' Intercultural Communication Ability under the Mode of Sino-Foreign Cooperative Education. Journal of Shenyang Normal University, 1-7.

[11] Qu, X.H. and Feng, Y. (2018) Study on the Development Path of China's Higher Education Internationalization. Learning and Exploration, No. 5, 32-37.

[12] Dong, L.F. and Wang, S.C. (2018) Strategic Thinking and Development Path of Internationalization Going Out. Adult Education in China, No. 15, 36-39.

[13] Dang, J. (2018) A Preliminary Study on the Development Path of Higher Education Internationalization in the New Era. Chinese Adult Education, No. 15, 79-81.

[14] Lai, W.B. and Zhang, N.Y. (2018) SPSS Analysis of the Internationalization Function of Local University Education. Journal of Shangrao Normal University, 38, 94-99. 
[15] Wu, Y. and Song, Y.H. (2018) The Basis, Dimension and Realization Path of the Connotative Development of Higher Education Internationalization. China Higher Education Research, No. 8, 17-22. 